\title{
直流放電場に対する高周波基板バイアスの影響 Influence of rf substrate biasing on dc discharge field
}

\author{
正 南部 健一 (東北大) $\bigcirc$ 学 後藤 康徳 (東北大) \\ Kenichi Nanbu and Yasunori Gotoh, Institute of Fluid Science, Tohoku University, Sendai 980-8577
}

The substrate biasing is a standard technique to control the energy of ions incident on a wafer. The effect of substrate biasing on dc discharge field is examined using the exact solution of the Poisson equation. It is found that the effect of biasing is not limited to the region near the substrate but biasing influences the whole discharge field.

Key Words : dc discharge, rf biasing, analytic solution

\section{1. 緒 言}

スパッタリング技術は現在様々な用途に利用されている。 ス パッタリングプロセスの基本は, ターゲットの表面から原子を たたき出すことであり,これによりターゲットをスパッタエッチ する.一方, スパッタデポジションは, ターゲットを飛び出した原 子のほうに着目したプロセスである.この原子は空間を飛行し， 基板の上に堆積する.この工程を繰り返すことによって, 薄膜 が作成できる．ここで, 基板に入射する粒子の量やエネルギー を制御して，膜の性質に様々な変化を及ほすことが期待できる. これを実現するのがバイアススパッタリング技術であり，基板 側に高周波バイアス電圧を付加する方法が一般的である(1).

この制御された荷電粒子の動向を探るにあたって, バイアス 電圧が装置全体の電位に及ほす影響を調べることは重要である。 本研究では, Fig.1 に示す円筒形の装置を想定し, 高周波基板 バイアスが装置内の電位に与える影響を解析的に解く。

\section{2. 理論計算}

空間の電荷密度が $\rho$ で与えられるとき, 空間内における電位 $\phi$ は，ポアソン方程式で規定される. 円筒座標系 $(r, \theta, z)$ におけ る電位は， $\theta$ に依らないとした場合，次のように表される。

$$
\left(\frac{\partial^{2}}{\partial r^{2}}+\frac{1}{r} \frac{\partial}{\partial r}+\frac{\partial^{2}}{\partial z^{2}}\right) \phi=-\frac{\rho}{\epsilon_{0}}
$$

ここで $\rho$ の分布は

$$
\begin{aligned}
\rho= & {\left[A e^{-\alpha(z / H)^{2}}\left(\sin \frac{\omega t}{2}\right)^{2}+B e^{-\beta(1-z / H)^{2}}\right] } \\
& \times\left(1-r^{2} / R^{2}\right)
\end{aligned}
$$

に従うと仮定し, Fig.2 にこの分布を示す.ここで, $A, B, \alpha, \beta$ は定数, $\epsilon_{0}$ :真空の誘電率, $\omega$ :角周波数. 次に, この方程式の解 を示す。

$$
\begin{aligned}
\phi & =\psi_{1}+\psi_{2}+\Psi \\
\psi_{1} & =\sum_{j=1}^{\infty} A_{j} J_{0}\left(x_{j} \frac{r}{R}\right) \sinh \left[\frac{x_{j}}{R}(H-z)\right] \\
\psi_{2} & =\sum_{j=1}^{\infty} B_{j} J_{0}\left(x_{j} \frac{r}{R}\right) \sinh \frac{x_{j} z}{R} \\
\Psi & =\sum_{j=1}^{\infty} \sum_{n=1}^{\infty} D_{n j} J_{0}\left(x_{j} \eta\right) \sin (n \pi \xi) \\
A_{j} & =\frac{2 \phi_{0}}{x_{j}} \frac{1}{\left(\sinh \frac{x_{j} H}{R}\right) J_{1}\left(x_{j}\right)}
\end{aligned}
$$

$$
\begin{aligned}
& B_{j}=\frac{2 V_{c}}{x_{j}} \frac{1}{\left(\sinh \frac{x_{j} H}{R}\right) J_{1}\left(x_{j}\right)} \\
& D_{n j}=\frac{C_{n j} / \epsilon_{0}}{\left(x_{j} / R\right)^{2}+(n \pi / H)^{2}} \\
& C_{n j}=\frac{16}{x_{j}^{3} J_{1}\left(x_{j}\right)} \int_{0}^{1} f(\xi, t) \sin n \pi \xi d \xi \\
& f(\xi, t)=A e^{-\alpha \xi^{2}}\left(\sin \frac{\omega t}{2}\right)^{2}+B e^{-\beta(1-\xi)^{2}} \\
& \phi_{0}=\phi(0, r)=V_{\mathrm{dc}}+V_{\mathrm{rf}} \cos \omega t \\
& \eta=\frac{r}{R}, \xi=\frac{z}{H} \\
& \text { ここで, } J_{n}: \text { ベッセル関数, } x_{j}: J_{0} \text { の零点. }
\end{aligned}
$$

\section{3. 計 算}

\section{1 計算条件}

まず，Fig.1のような装置を用いるとする．各パラメータを $R=H=200 \mathrm{~mm}, V_{\mathrm{c}}=270 \mathrm{~V}, V_{\mathrm{dc}}=-62 \mathrm{~V}, V_{\mathrm{rf}}=100 \mathrm{~V}$, $f=13.56 \mathrm{MHz}$ とした. また, $A=B=5 \times 10^{-6} \mathrm{C} / \mathrm{m}^{3}$, $\alpha=\beta=200$ とする ${ }^{(2)}$.

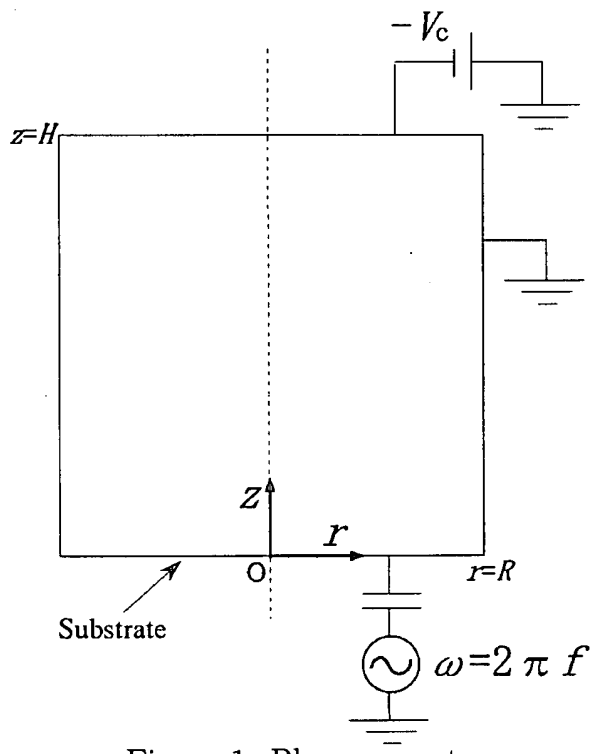

Figure 1: Plasma reactor. 


\section{2 計算結果}

Fig.3〜6に, $r=0$ における $\psi_{1}, \psi_{2}, \Psi$ および $\phi$ の $z$ 方向への 変化を示す.

バイアス電圧が時間的に変化すると, 反応器内の電位は, 陰極 付近を除き大きく変化することが分かる。

\section{4. 結 言}

計算結果より, バイアスの影響は, 反応器内全体に浸透して いることが分かった．高周波バイアスは，器内の電位を制御し， これにより基板への荷電粒子のエネルギーを制御するのに有効 な手段と言える.

\section{参考文献}

(1) 岡本 幸雄:プラズマプロセシングの基礎.

（2）北谷 募规:高周波放電の粒子シミュレーション法による研 究 (平成 7 年度修士学位論文).

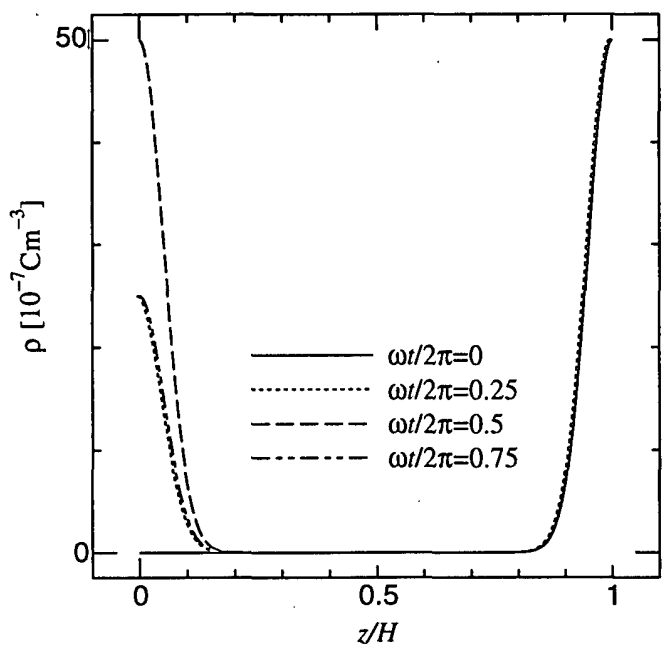

Figure 2: Charge density at $r=0$.

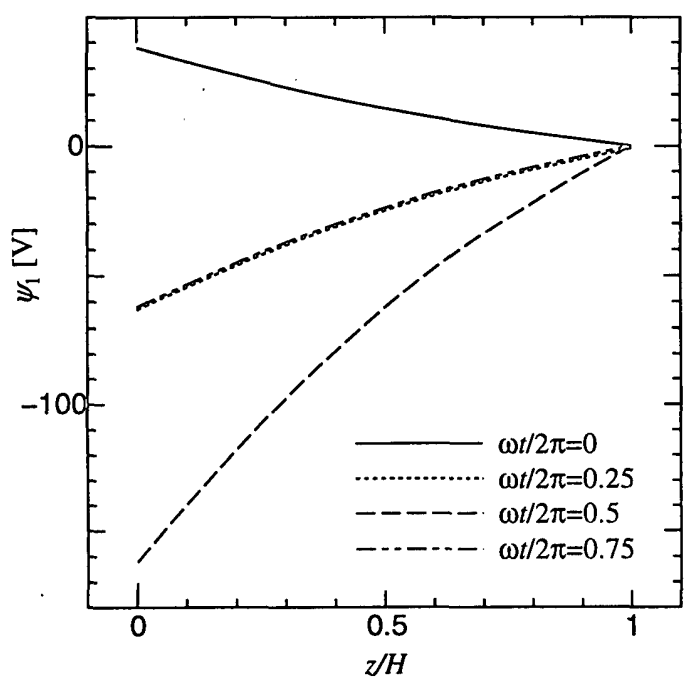

Figure 3: $\psi_{1}$ at $r=0$.

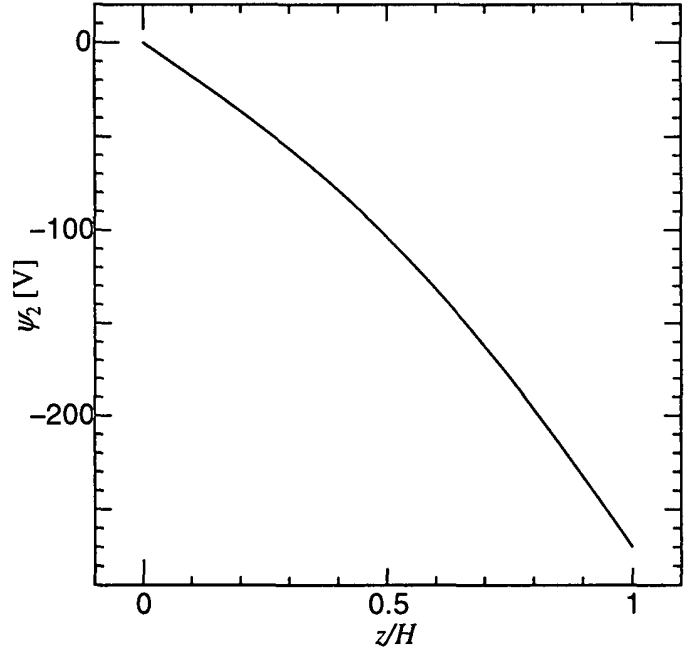

Figure 4: $\psi_{2}$ at $r=0$.



Figure 5: $\Psi$ at $r=0$.

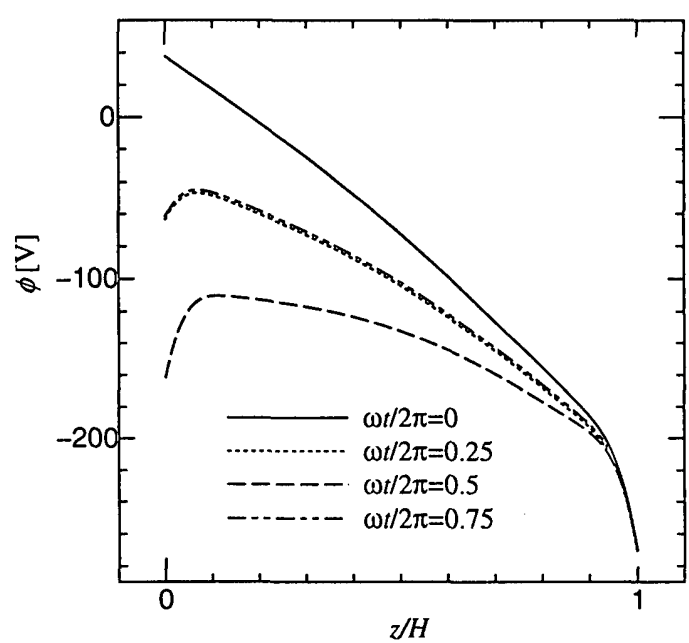

Figure 6: $\phi$ at $r=0$ 